\title{
Modelling of the air pollutants' cold-start emissions depending on average vehicles' speed
}

ARTICLE INFO

Received: 14 July 2021

Revised: 10 August 2021

Accepted: 12 September 2021

Available online: 15 September 2021
The aim of the study is to present the results of mathematically modeled influence of the average speed on the pollutant released in the air during the cold-start process. There were taken into consideration the emission from the passenger cars (PCs) for the different fuel types, vehicles' segments (including hybrid), and the Euro standard. In the article the simulations was performed using the COPERT software, as well as WLTP-based research. The modelling results there are presented show that the change in average speed has a significant effect on air pollutant $\left(\mathrm{CO}_{2}, \mathrm{NO}_{x}, \mathrm{NMVOC}, \mathrm{CO}\right)$ emissions released in cold-start process. Furthermore, the results show that pollutants' emissions are sensitive to average speed fluctuations.

Key words: air pollutant, vehicle, cold-start emission, hybrid

This is an open access article under the CC BY license (http://creativecommons.org/licenses/BY/4.0/)

\section{Introduction}

Passenger cars' emissions are largely responsible for emissions from the road transport sector which is a significant source of air pollutants as: $\mathrm{CO}_{2}, \mathrm{NO}_{\mathrm{x}}, \mathrm{NMVOC}$ and CO. All of these pollutants are harmful to the environment and human health, contribute to the greenhouse effect and affect air quality. Emissions from road transport is particularly troublesome in cities, where it significantly deteriorates the air quality. Emissions from motor vehicles arise mainly during two states of combustion engine operation: hot and cold-start emissions [5]. In modern vehicles emissions released into the air during the hot start (when the engine is at its normal operating temperature) are relatively small in comparison to cold-start emissions, and constantly decreasing during the trip. For this reason the cold-start emissions have become important $[1,8,13,16]$. The cold-start emissions can be defined as the total mass of the individual pollutants generated under the operating conditions of a thermally unstable engine almost after the engine is started. [9]. Coldstart emissions can be also defined as 'excess' emissions, i.e. they are significant compared to the emissions produced when an engine is in a fully warmed-up operational state. However, taking into consideration the duration of any period of driving, the significance of cold-start emissions decreases as the duration and distance of a period of driving increase. Cold-start emissions arise at the initial start-up when the engine is cold - starting from the ambient temperature (Ta), their value can be expressed as a mass of pollutant(s) per the vehicle start [9]. During a hot start, the temperatures of the oil, coolant and all the elements of the engine are very close to those observed during a fully warmed-up operation (Tw). The term cool start can be used to refer to an engine's start in the intermediate temperatures, i.e. $\mathrm{Ta}<\mathrm{T}<\mathrm{Tw}$, where $\mathrm{T}$ is the temperature of a given engine [9].

The bad air quality in urbanized areas is often dominated by these cold-start emissions which also contributes to formation of secondary aerosols [8, 13, 16].
It is especially important at low and average speed which are typical for cars usage in cities. It is also known that the emission of air pollutants depends on the type of fuel, and the Euro standard of the vehicles [2-4, 13].

\section{Methodology}

In this paper for purposes of simulation authors use the COPERT 5.4 software. The methodology used in the COPERT model are in accordance with the guidelines from EMEP Guidebook 2019 [5, 12] and widely applied in European countries. In the following Tier 3 approach, the total exhaust emissions from road transport are estimated as the sum of hot-start and cold-start emissions (during transient thermal engine operation) [5].

The general equation for the 'Tier 3' methodology is presented below:

$$
\mathrm{E}_{\text {Total }}=\mathrm{E}_{\text {Hot }}+\mathrm{E}_{\text {Cold }}
$$

where: $\mathrm{E}_{\text {Total }}$ - total emissions $[\mathrm{g}$ ] of any pollutant for the spatial and temporal resolution of the application, $\mathrm{E}_{\mathrm{Hot}}$ emissions $\left[\mathrm{g}\right.$ ] during stabilized (hot) engine operation, $\mathrm{E}_{\text {Cold }}$ - emissions [g] during transient thermal engine operation (cold start).

Additionally, cold-start emission occurring manly to urban driving condition, rarely in rural driving and in limited number of trips start at highway conditions. That's mean the total exhaust emission can by calculated by the equation [5]:

$$
\mathrm{E}_{\text {Total }}=\mathrm{E}_{\text {Urban }}+\mathrm{E}_{\text {Rural }}+\mathrm{E}_{\text {Highway }}
$$

where: $\mathrm{E}_{\mathrm{Urban}}, \mathrm{E}_{\text {Rural }}, \mathrm{E}_{\text {Highway }}$ - are the total emissions [g] of any pollutant the respective driving situations.

According to the 'tier 3' methodology cold-start emission is an additional emissions, which take place under all driving conditions (but most likely for urban and rural driving, as the number of starts in highway conditions is relatively limited).

Cold-start emission occur in all vehicles category, but in "EMEP/EEA air pollutant emission inventory guidebook 2019 " there are available emission factors for petrol, diesel 
and LPG passenger cars and light commercial vehicles, therefore only for these categories are covered by the methodology. Moreover, they are not considered to be a function of vehicle age.

According to the 'tier 3' methodology cold-start emissions are calculated as an extra emission over the emissions that would be expected if all vehicles were only operated with hot engines and warmed-up catalysts. A relevant factor, corresponding to the ratio of cold over hot emissions, is applied to the fraction of kilometres driven with a cold engine. This factor varies from country to country. Driving behaviour (varying trip lengths) and climatic conditions affect the time required to warm up the engine and/or the catalyst, and hence the fraction of a trip driven with a cold engine [5].

$$
\mathrm{E}_{\text {Cold; } \mid \mathrm{i}, \mathrm{j}}=\beta_{\mathrm{i}, \mathrm{k}} \cdot \mathrm{N}_{\mathrm{k}} \cdot \mathrm{M}_{\mathrm{k}} \cdot \mathrm{e}_{\mathrm{Hot} ; \mathrm{i}, \mathrm{k}} \cdot\left(\left.\frac{\mathrm{e}^{\text {Cold }}}{\mathrm{e}^{\mathrm{Hot}}}\right|_{\mathrm{i}, \mathrm{k}}-1\right)
$$

$\mathrm{E}_{\text {Cold;|i,j }}$ - cold-start emissions of pollutant $\mathrm{i}$ (for the reference year), produced by vehicle technology $\mathrm{k}, \beta_{\mathrm{i}, \mathrm{k}}-$ fraction of mileage driven with a cold engine or the catalyst operated below the light-off temperature for pollutant $i$ and vehicle technology $\mathrm{k}, \mathrm{N}_{\mathrm{k}}$ - number of vehicles [veh] of technology $\mathrm{k}$ in circulation, $\mathrm{M}_{\mathrm{k}}$ - total mileage per vehicle $[\mathrm{km} / \mathrm{veh}]$ in vehicle technology $\mathrm{k}, \mathrm{e}_{\mathrm{Hot} ; \mathrm{i}, \mathrm{k}}-$ hot emission factor for pollutant $i$ and vehicles of $k$ technology, $\frac{e^{\text {Cold }}}{e^{\mathrm{Hot}}} \mid i, k$ - cold/hot emission quotient for pollutant $i$ and vehicles of $\mathrm{k}$ technology.

The $\beta$ parameter depends on the ambient temperature (in COPERT software is using the average monthly temperature), the conditions (pattern) of the vehicle use that's means the average trip length $1_{\text {trip }}$. However, the information on $1_{\text {trip }}$ is not available in Poland for all vehicle classes. According to the available statistical data and the default value of COPERT software author use the value of $12 \mathrm{~km}$ [5].

It should be emphasized that all of the emissions factors included in the COPERT model are determined on the basis of laboratory testing in accordance with the WLTP driving cycle [9].

In this paper, the authors investigated the impact of changes in average speed on the cold-start emissions of $\mathrm{CO}_{2}, \mathrm{NO}_{\mathrm{x}}, \mathrm{NMVOC}$ and $\mathrm{CO}$ in passenger cars (PCs), for particular Euro standards, vehicles' segments and different fuel types. In the Table 1 there are shown the types of vehicles considered in the simulation.

Table 1. Types of the passenger cars considered in the simulation

\begin{tabular}{|l|l|l|}
\hline Fuel & Segment & Euro Standard \\
\hline Petrol & $\begin{array}{l}\text { Mini, Small, Medium, } \\
\text { Large-SUV-Executive }\end{array}$ & Euro 1 - Euro 6 \\
\hline Petrol HEV & $\begin{array}{l}\text { Mini, Small, Medium, } \\
\text { Large-SUV-Executive }\end{array}$ & Euro 4 - Euro 6 \\
\hline Diesel & $\begin{array}{l}\text { Mini, Small, Medium, } \\
\text { Large-SUV-Executive }\end{array}$ & Euro 1 - Euro 6 \\
\hline LPG Bifuel & $\begin{array}{l}\text { Mini, Small, Medium, } \\
\text { Large-SUV-Executive }\end{array}$ & Euro 1 - Euro 6 \\
\hline CNG Bifuel & $\begin{array}{l}\text { Mini, Small, Medium, } \\
\text { Large-SUV-Executive }\end{array}$ & Euro 4 - Euro 6 \\
\hline
\end{tabular}

Calculations carried out using the COPERT software were based on the actual input data used for the compilation of Polish national emission inventory for 2019 [10]. The estimations are conducted for the basic assumptions on share per road class (urban, rural and highways) (Fig. 1), as well as the maximum and minimum temperatures occurring in Poland in 2019 [6, 7] (Table 2). The data is given below.

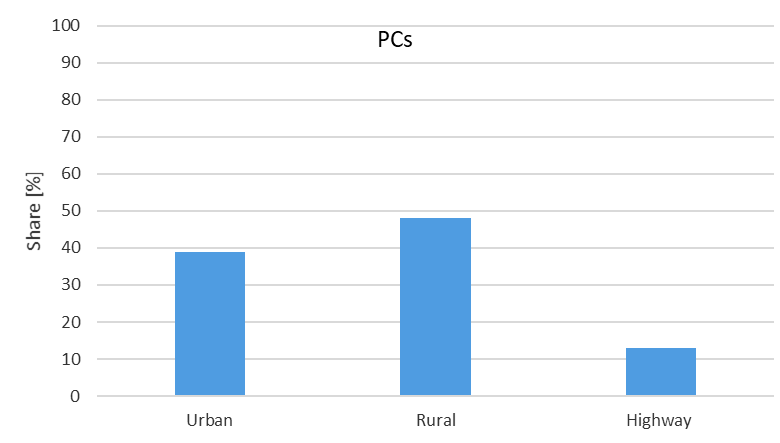

Fig. 1. Mileage share per road class

Table 2. Average monthly temperatures in Poland in 2019

\begin{tabular}{|l|c|c|}
\hline Month & Min & Max \\
\hline January & -8.5 & 1.2 \\
\hline February & -2.8 & 4 \\
\hline March & -2.9 & 7.2 \\
\hline April & 0.8 & 11.2 \\
\hline May & 1.9 & 13.8 \\
\hline June & 12.5 & 23.3 \\
\hline July & 9.7 & 20.3 \\
\hline August & 11 & 21.2 \\
\hline September & 5.7 & 15.2 \\
\hline October & 4 & 11.5 \\
\hline November & -0.7 & 7.9 \\
\hline December & -3.1 & 4.8 \\
\hline
\end{tabular}

Based on the various traffic situation in Polish cities authors want to check how big is the impact of the average speed on the cold-start emissions. The simulations are performed assuming average speed changing from $5 \mathrm{~km} / \mathrm{h}$ to $45 \mathrm{~km} / \mathrm{h}$ with $5 \mathrm{~km} / \mathrm{h}$ intervals. The simulations were performed with the assumption that the engine warm-up time does not change.

\section{Results}

The comparison of cold-start emissions for $\mathrm{CO}_{2}$, depending on average speed for the Euro standard is shown in the Figs 2-5, for the vehicle segment in the Figs 6-9 and for the fuel type in the Fig. 10.

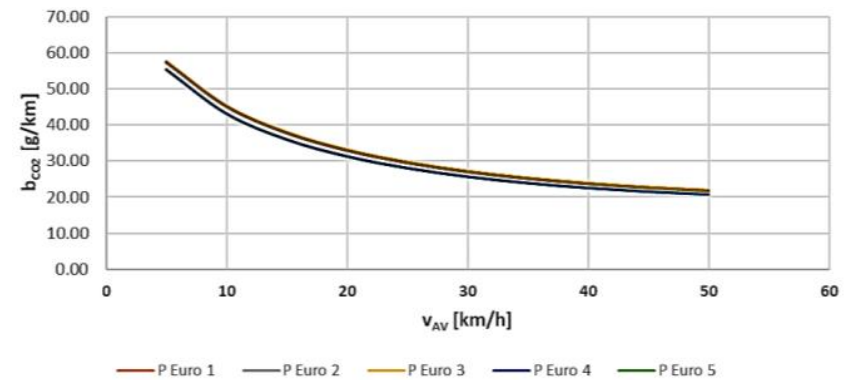

-PEuro 6 - HEVEuro 4 - HEVEuro 5 - HEV Euro 6

Fig. 2. $\mathrm{CO}_{2}$ emission from petrol PCs for Euro standards depending on average speed 


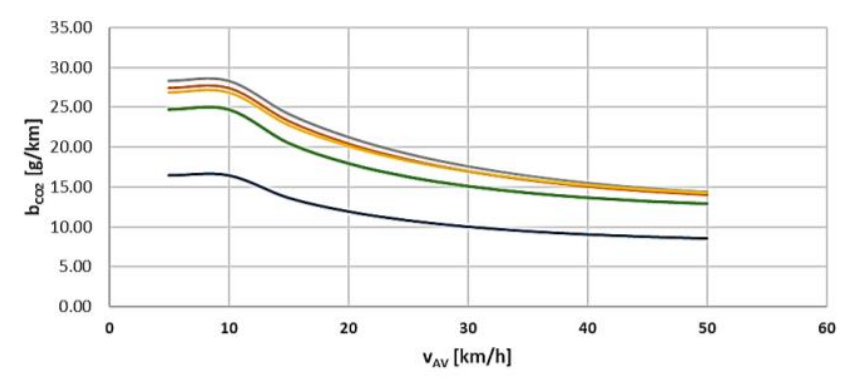

-DEuro 1 -DEuro 2 -DEuro 3 -DEuro 4 -DEuro 5 -DEuro 6

Fig. 3. $\mathrm{CO}_{2}$ emission from diesel oil PCs for Euro standards depending on average speed

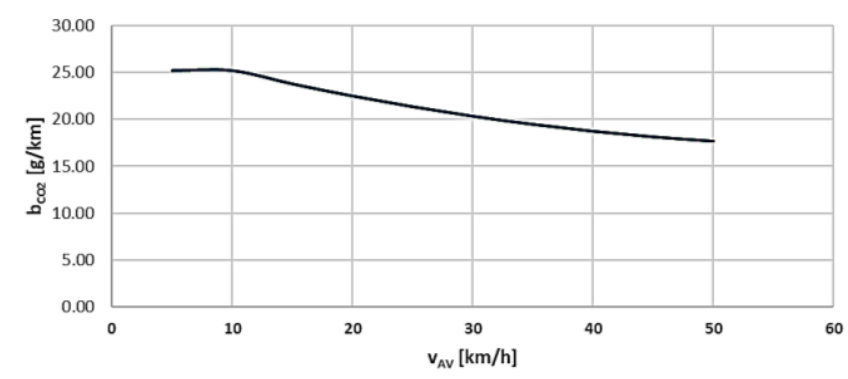

—LPG Euro 1 -LPG Euro 2 -LPG Euro 3 -LPGEuro 4 -LPGEuro 5 -LPG Euro 6

Fig. 4. $\mathrm{CO}_{2}$ emission from LPG PCs for Euro standards depending on average speed

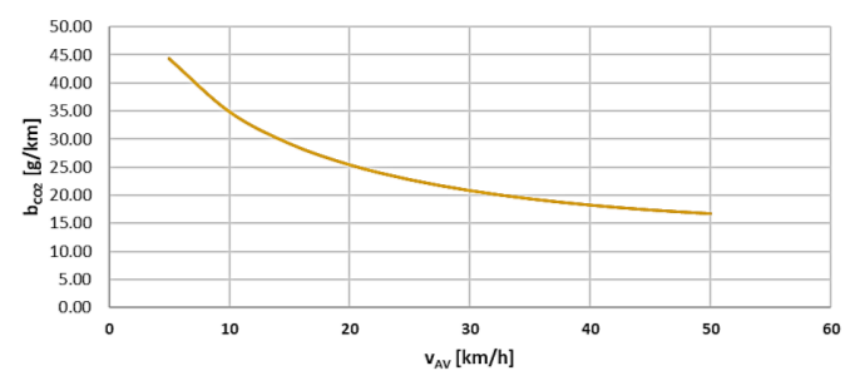

—CNG Euro 4 - CNG Euro 5 CNG Euro 6

Fig. 5. $\mathrm{CO}_{2}$ emission from CNG PCs for Euro standards depending on average speed

In the above figures it can be seen that for all fuels types, the $\mathrm{CO}_{2}$ emissions decreases with the increase of the average speed. The cold start emission from PCs CNG and PCs LPG has the same value for all Euro standards, for PCs petrol there is small difference between the Euro standards, the greatest difference is visible for PCs diesel, where for the Euro 1 standard the cold start emission is the highest.

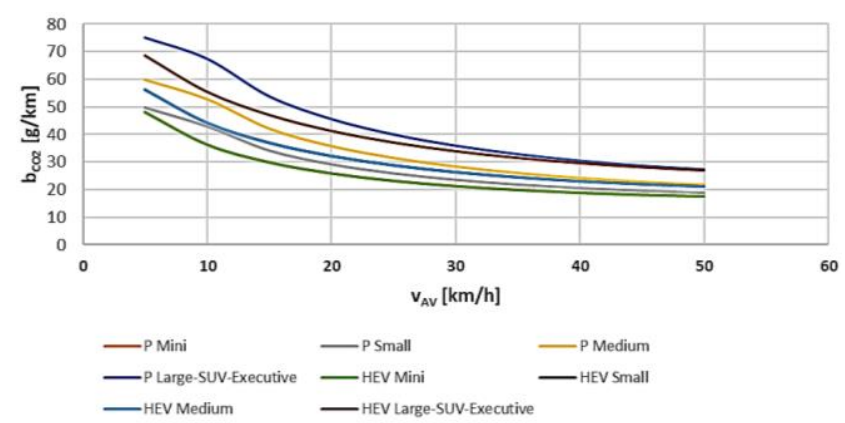

Fig. 6. $\mathrm{CO}_{2}$ emission from petrol PCs for vehicle depending on average speed

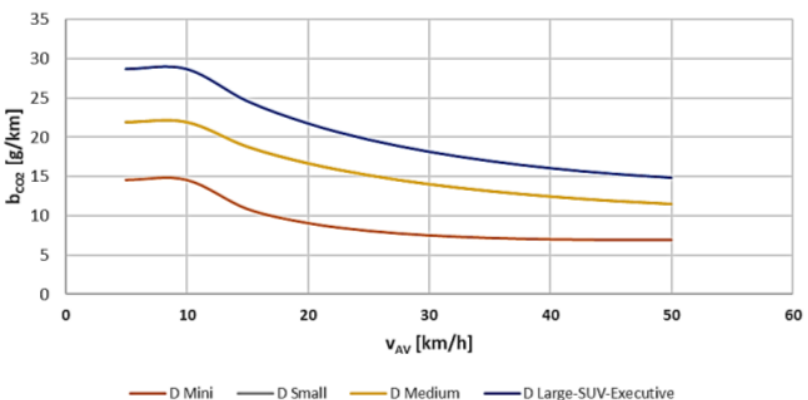

Fig. 7. $\mathrm{CO}_{2}$ emission from diesel oil PCs for vehicle depending on average speed

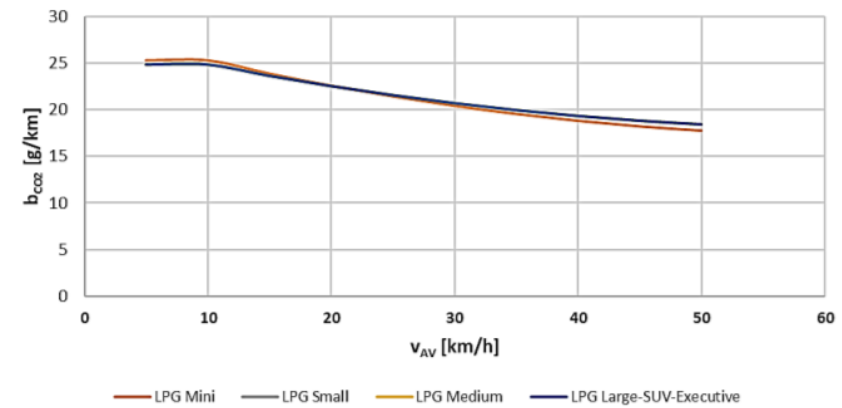

Fig. 8. $\mathrm{CO}_{2}$ emission from LPG PCs for vehicle depending on average speed

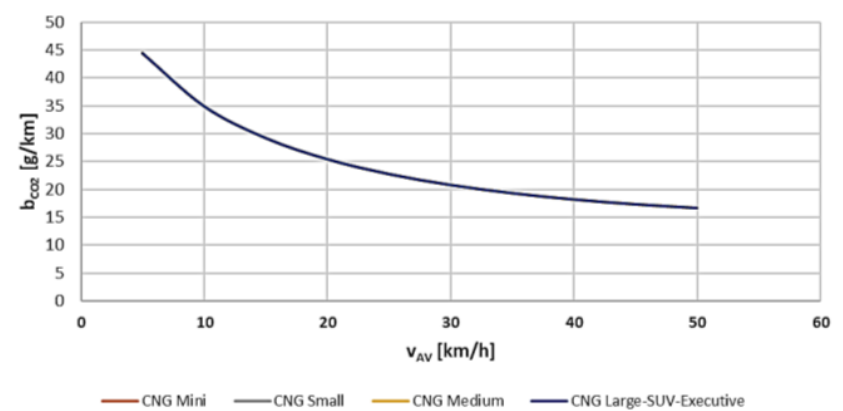

Fig. 9. $\mathrm{CO}_{2}$ emission from $\mathrm{CNG}$ PCs for vehicle segments depending on average speed

The Figures 7-9 shows the dependence of $\mathrm{CO}_{2}$ emissions on the average speed for the passenger car segments. The lowest emission is for the "Mini" and "Small" segment (for petrol, the emissions from the "Mini" and "Small" are the same, and for diesel, the emissions from the "Small" and "Medium" are the same). For CNG and LPG, there is no difference between the segments for cold start emissions.

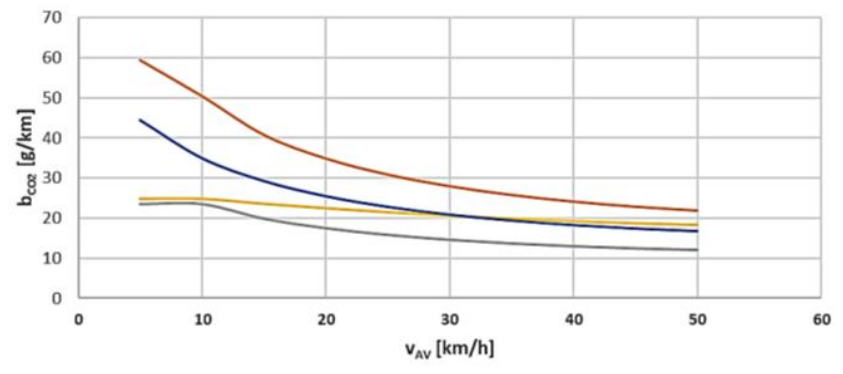

- Petrol —Diesel — LPG —CNG

Fig. 10. $\mathrm{CO}_{2}$ emission from PCs for fuel type depending on average speed 
It is clearly visible that as the average speed increases, the cold-start emission decreases. The figure shows the sensitivity of cold-start emissions to the vehicle segment, moreover, that the lowest cold-start emission is for diesel oil and LPG.

In the Figures 11-14 are shown a comparison of $\mathrm{NO}_{\mathrm{x}}$ cold-start emissions for Euro standard depending on the average speed, in the Figs are $15-18$ for the vehicle segment and for the fuel type in the Fig. 19.

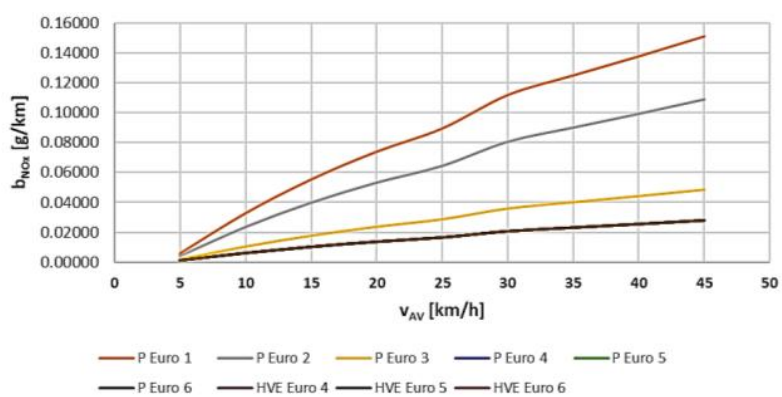

Fig. 11. $\mathrm{NO}_{\mathrm{x}}$ emission from petrol PCs for Euro standards depending on average speed

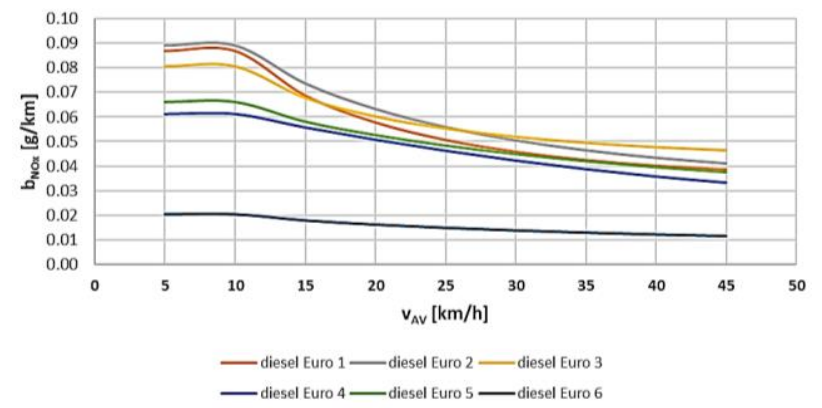

Fig. 12. $\mathrm{NO}_{\mathrm{x}}$ emission from diesel oil PCs for Euro standards depending on average speed

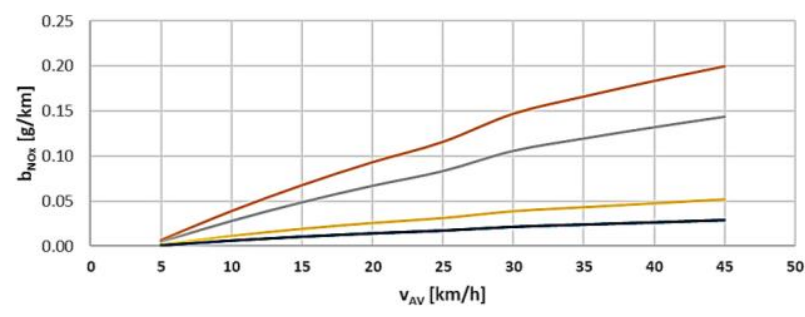

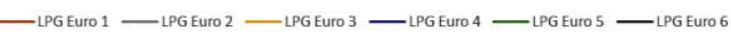

Fig. 13. $\mathrm{NO}_{\mathrm{x}}$ emission from LPG PCs for Euro standards depending on average speed

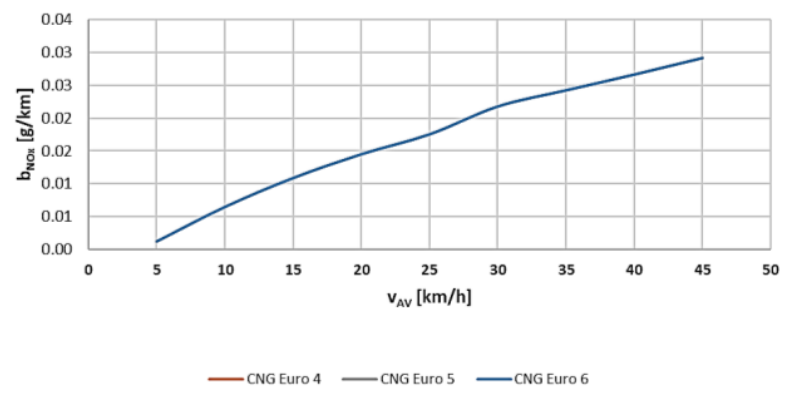

Fig. 14. $\mathrm{NO}_{\mathrm{x}}$ emission from CNG PCs for Euro standards depending on average speed
In the Figures 11-14 it can be seen that for only for diesel the $\mathrm{NO}_{\mathrm{x}}$ emissions decreases with the increase of the average speed and for petrol, CNG and LPG emission grows. The cold start emission from PCs CNG as the same value for all Euro standards.

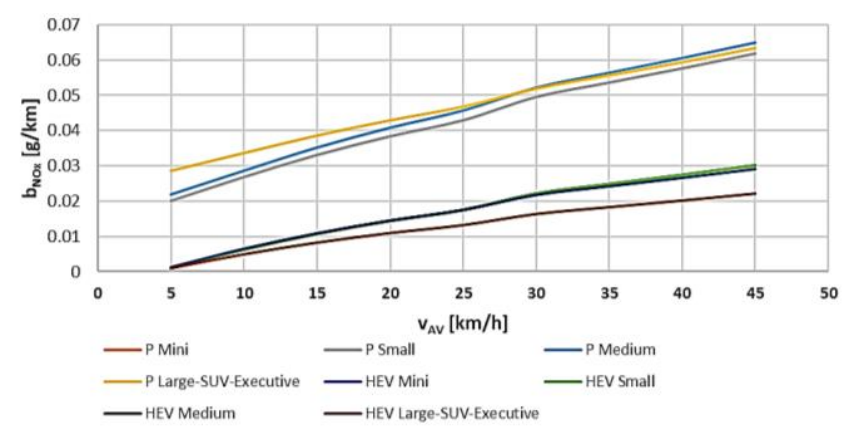

Fig. 15. $\mathrm{NO}_{\mathrm{x}}$ emission from petrol PCs for vehicle segments depending on average speed

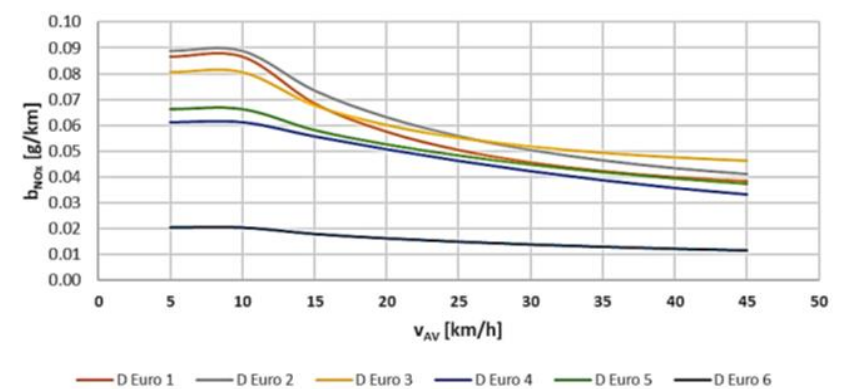

Fig. 16. $\mathrm{NO}_{\mathrm{x}}$ emission from diesel oil PCs for vehicle segments depending on average speed

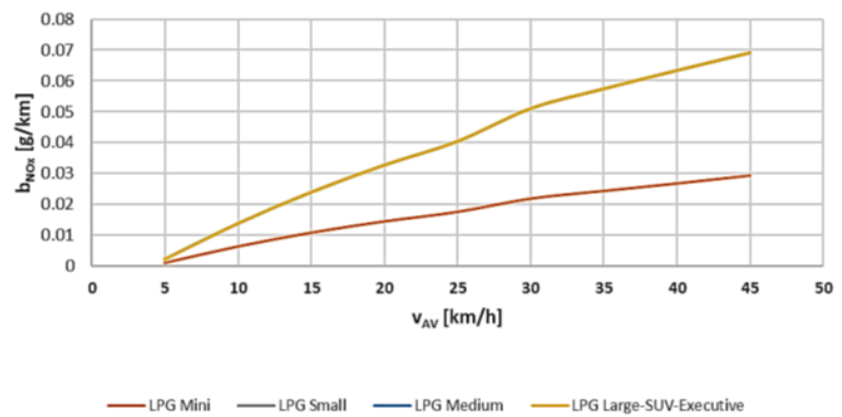

Fig. 17. $\mathrm{NO}_{\mathrm{x}}$ emission from LPG PCs for vehicle segments depending on average speed

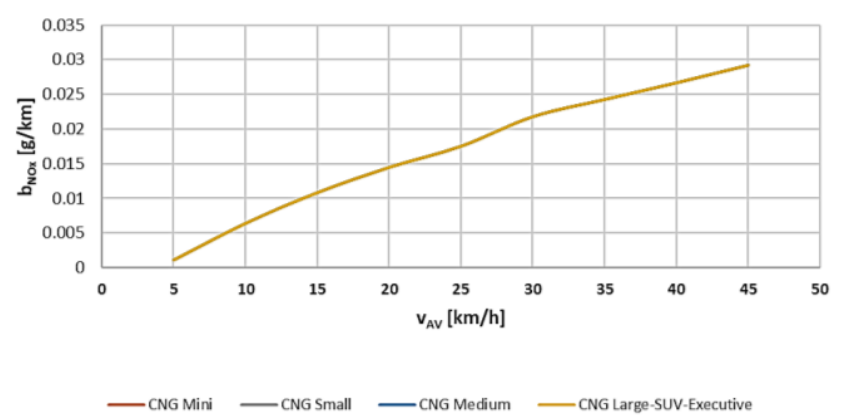

Fig. 18. $\mathrm{NO}_{\mathrm{x}}$ emission from $\mathrm{CNG}$ PCs for vehicle segments depending on average speed 
The Figure 16-18 shows the dependence of $\mathrm{NO}_{\mathrm{x}}$ emissions on the average speed for the passenger car segments. For PCs CNG, there is no difference between the segments for cold start emissions.

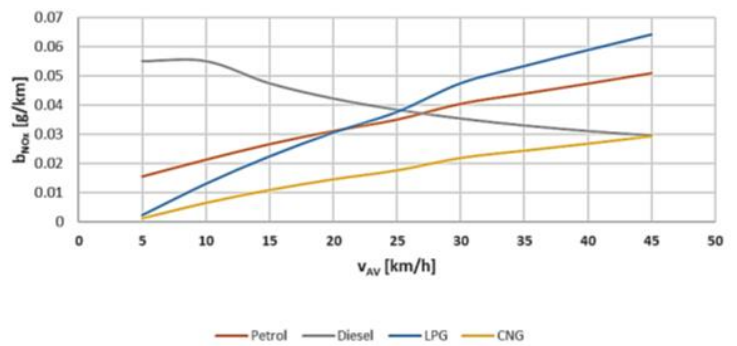

Fig. 19. $\mathrm{NO}_{\mathrm{x}}$ emission from PCs for fuel type depending on average speed

Unlike $\mathrm{CO}_{2}$ cold-start emissions, $\mathrm{NO}_{\mathrm{x}}$ emissions increase with the average speed for all fuels types except diesel, this is the case for all euro standards and vehicles segments.

The comparison of cold-start emissions for $\mathrm{CO}_{2}$, depending on average speed for the Euro standard is shown in the Figs 20-23, for the vehicle segment in the Figs 24-27 and for the fuel type in the Fig. 28.

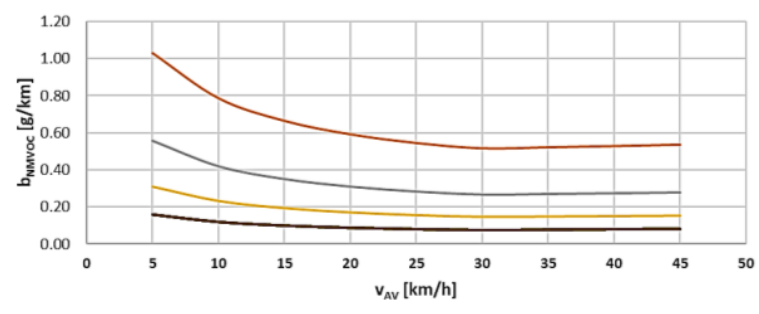

-PEuro 1 -PEuro 2 -PEuro 3 -PEuro 4 -PEuro 5

Fig. 20. NMVOC emission from petrol PCs for Euro standards depending on average speed

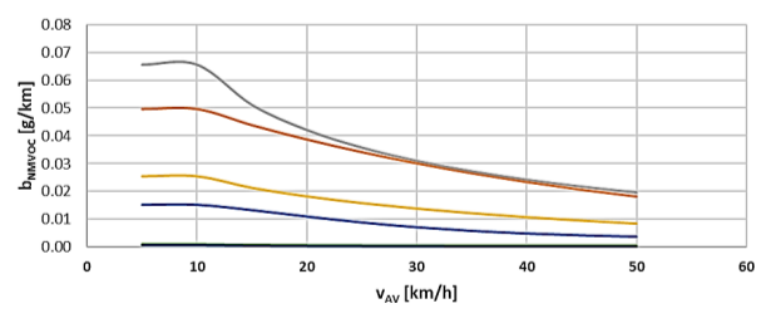

— diesel Euro 1 — diesel Euro 2 — diesel Euro 3

— diesel Euro 4 — diesel Euro 5 — diesel Euro 6

Fig. 21. NMVOC emission from diesel oil PCs for Euro standards depending on average speed

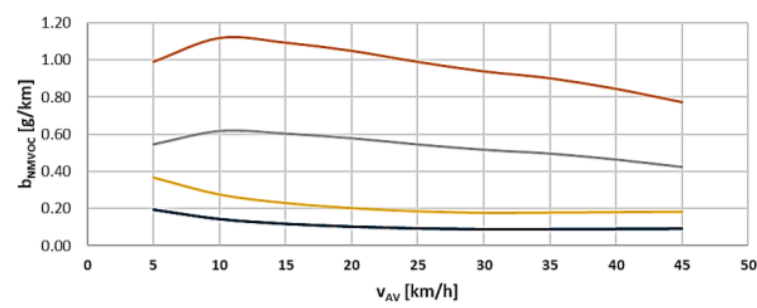

-LPG Euro 1 -LPG Euro 2 -LPG Euro 3 -LPG Euro 4 —LPG Euro 5 —LPG Euro 6

Fig. 22. NMVOC emission from LPG PCs for Euro standards depending on average speed

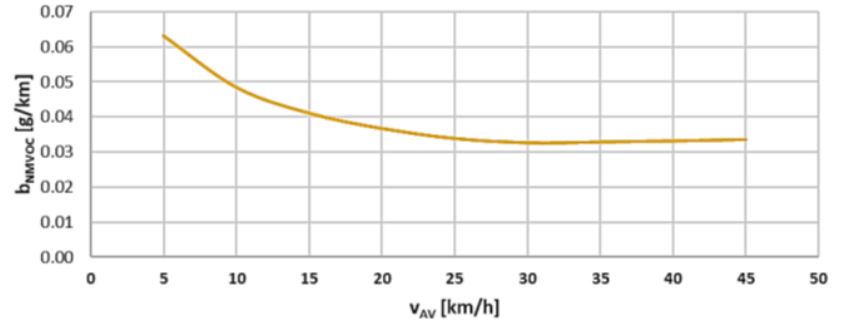

—CNG Euro 4 -CNG Euro 5 —CNG Euro6

Fig. 23. NMVOC emission from CNG PCs for Euro standards depending on average speed

In the figures above it can be seen that for all fuels types NMVOC emissions decreases with the increase of the average speed for petrol, CNG and LPG emission grows. The cold start emission from PCs CNG as the same value for all Euro standards.

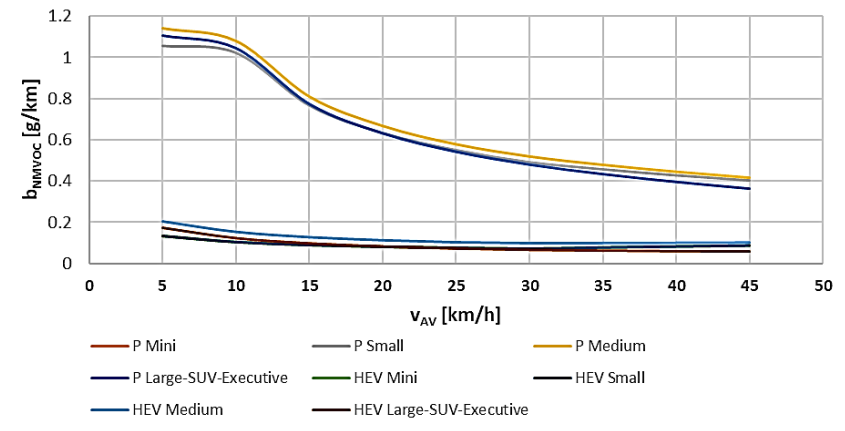

Fig. 24. NMVOC emission from petrol PCs for vehicle segments depending on average speed

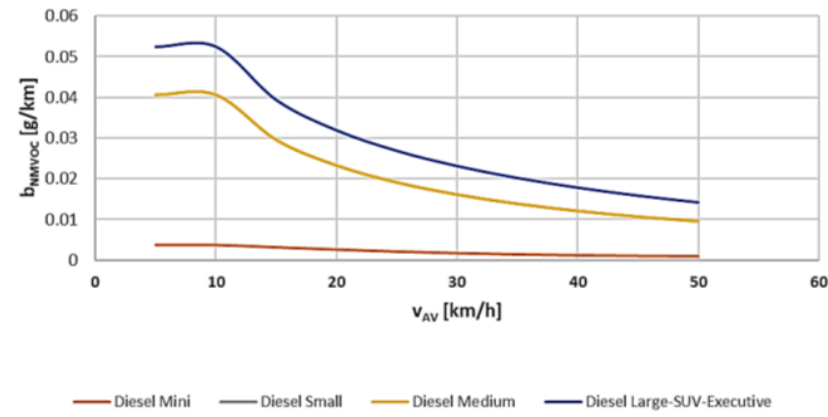

Fig. 25. NMVOC emission from diesel oil PCs for vehicle segments depending on average speed

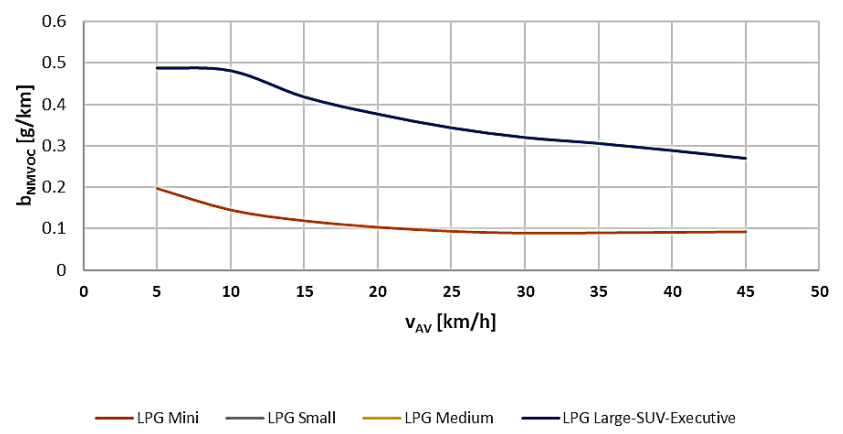

Fig. 26. NMVOC emission from LPG PCs for vehicle segments depending on average speed 


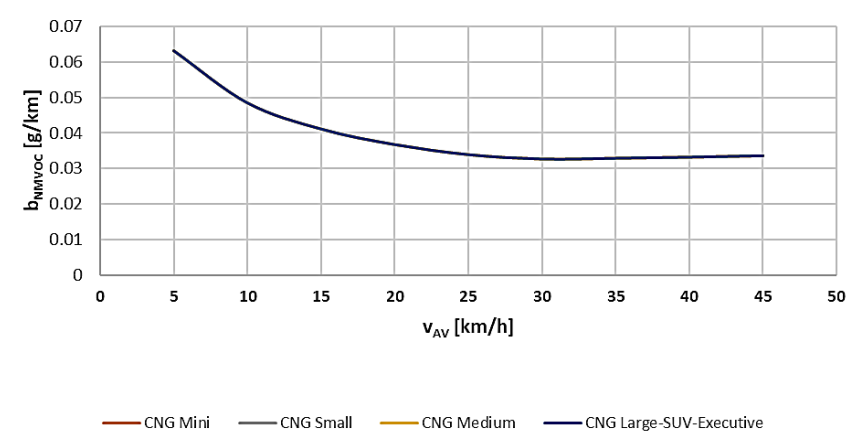

Fig. 27. NMVOC emission from CNG PCs for vehicle segments depending on average speed

On the Figure 24-27 it can be seen the dependence of NMVOC emissions on the average speed for PCs segments. For PCs CNG, there is no difference between the segments for cold start emissions.

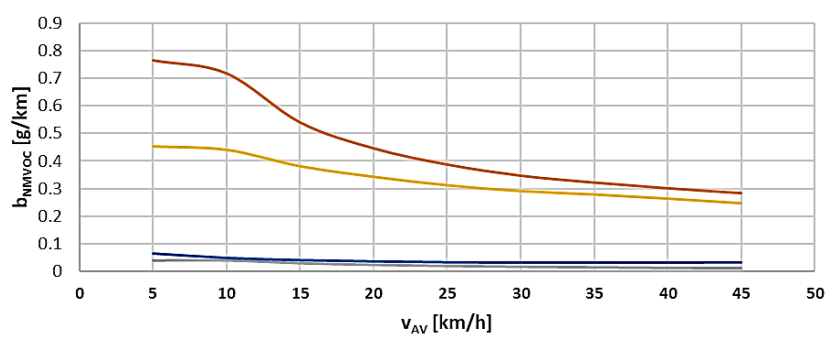

- Petrol —Diesel — ${ }_{\mathrm{LPG}}-\mathrm{CNG}$

Fig. 28. NMVOC emission from PCs for fuel type depending on average speed

The figures above show that the NMVOC emissions decrease with speed for all types of fuel in all categories and segments. It should also be noted that standards for Euro 4-Euro 6 no difference in emissions.

In the Figures 29-32 are shown a comparison of NMVOC cold-start emissions for Euro standard depending on average speed, $n$ the Figures are 33-36 for the vehicle segment and for the fuel type in the Fig. 37.

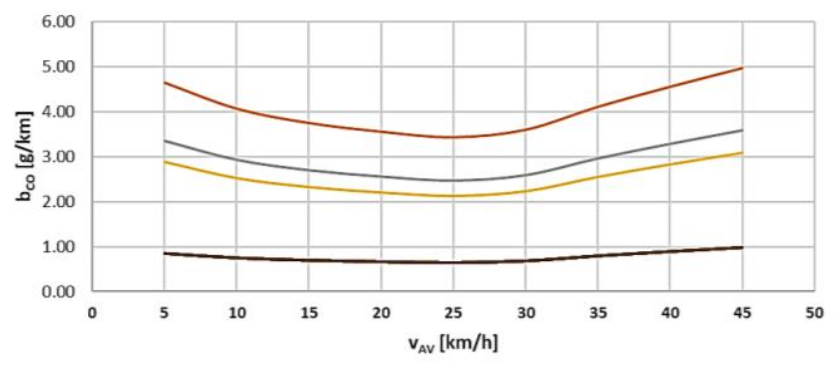

$$
\text { -PEuro } 1 \text {-PEuro } 2 \text {-PEuro } 3 \text {-PEuro } 4 \text {-PEuro } 5
$$

Fig. 29. CO emission from petrol PCs for Euro standards depending on average speed

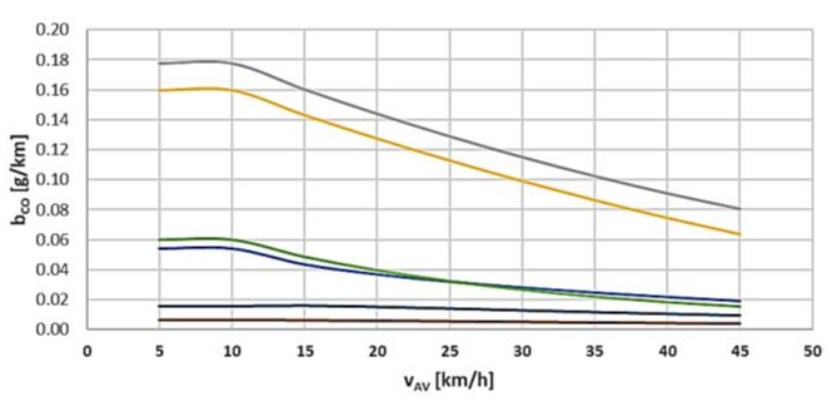

-DEuro 1 -DEuro 2 -DEuro3 -DEuro 4 -DEuro5 —DEuro 6

Fig. 30. CO emission from diesel oil PCs for Euro standards depending on average speed

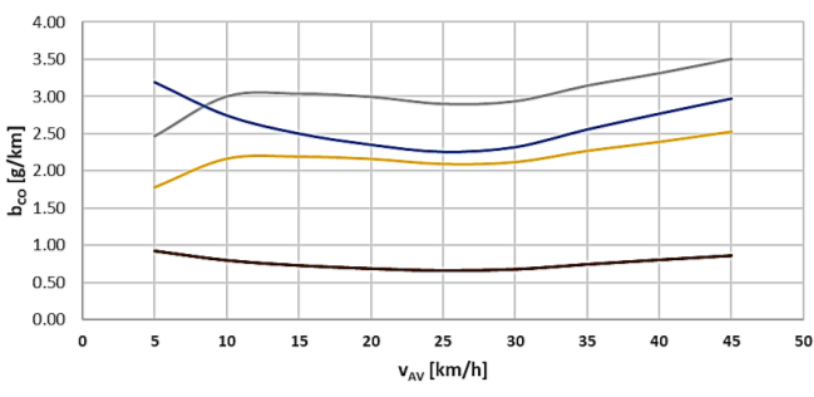

—LPG Euro 1 -LPG Euro 2 —LPG Euro 3 —LPG Euro 4 —LPG Euro 5 -LPG Euro 6

Fig. 31. CO emission from LPG PCs for Euro standards depending on average speed

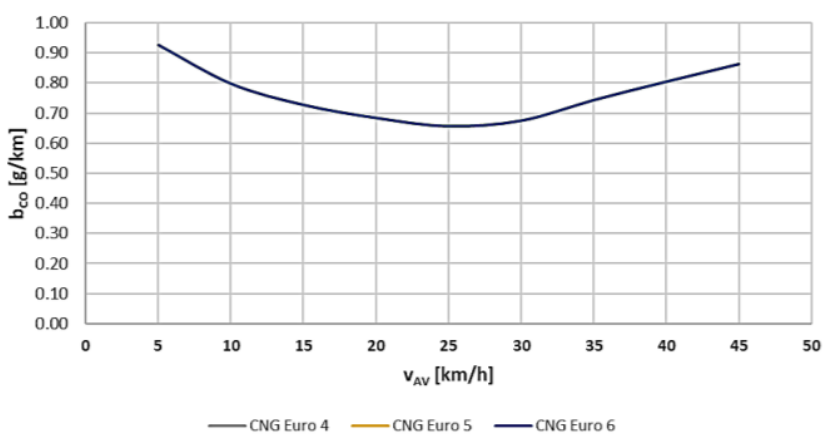

Fig. 32. CO emission from CNG PCs for Euro standards depending on average speed

The figures show the dependence of $\mathrm{CO}$ emissions for various euro categories on the average speed. The cold start emission from PCs CNG as the same value for all Euro standards.

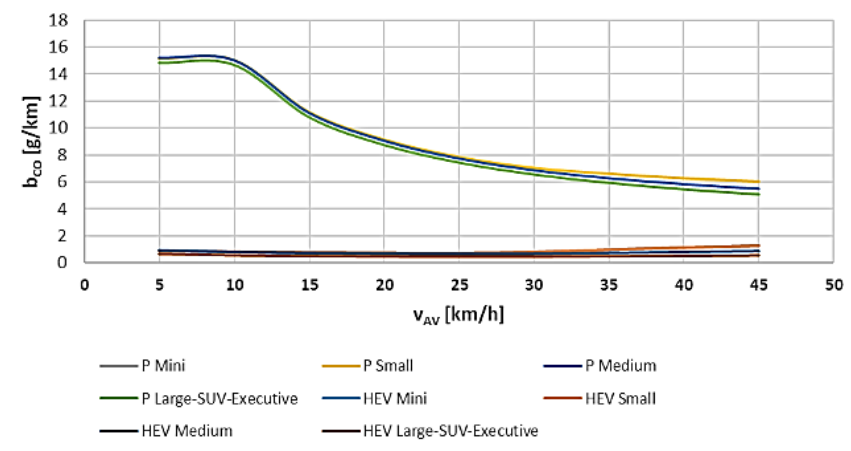

Fig. 33. CO emission from petrol PCs for vehicle segments depending on average speed 


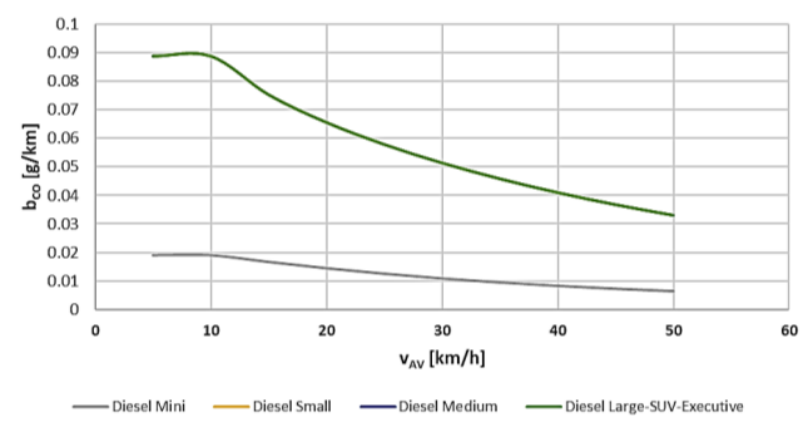

Fig. 34. CO emission from diesel oil PCs for vehicle segments depending on average speed

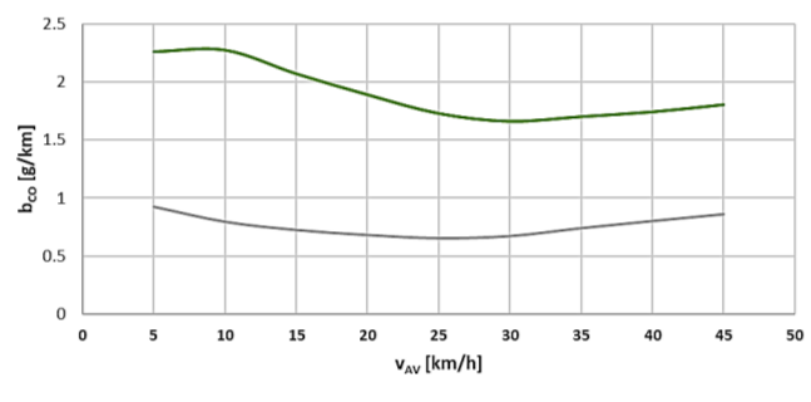

—LPG Mini —LPG Small -LPG Medium -LPG Large-SUV-Executive

Fig. 35. CO emission from LPG PCs for vehicle segments depending on average speed

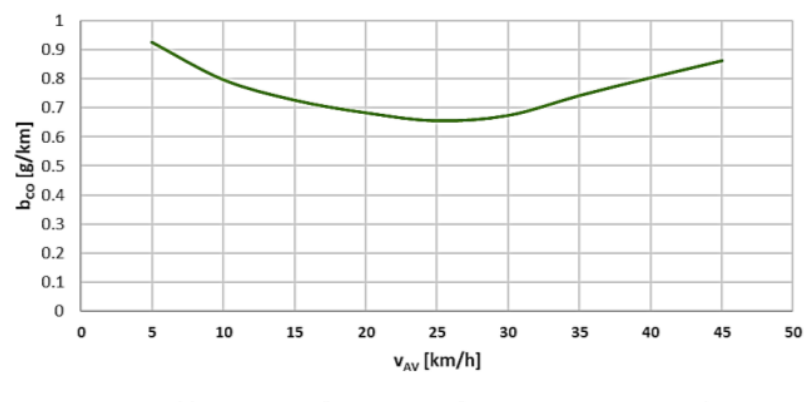

Fig. 36. CO emission from CNG PCs for vehicle segments depending on average speed
On the figure above it can be seen the dependence of $\mathrm{CO}$ emissions on the average speed for PCs segments. For "Mini" and "Small" and for "Medium" and "Large-SUVExecutive" for diesel and LPG the values are on the same level. For PCs CNG, there is no difference between the segments for cold start emissions.

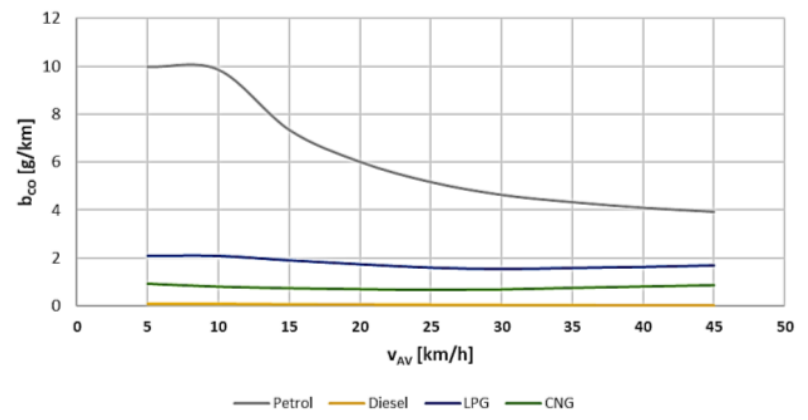

Fig. 37. $\mathrm{CO}$ emission from PCs for fuel type depending on average speed

The figures above show that the $\mathrm{CO}$ emissions decrease with speed for all types of fuel in all categories and segments. It should also be noted that standards for petrol $\mathrm{CO}$ cold-stare emission is higher than for another fuel.

\section{Conclusions}

The results of modelling indicate that in case of $\mathrm{CO}_{2}$, NMVOC, CO are decreasing with the increasing of average speed. There is a difference between euro standard, for the Euro 1-3 cold-start emission is higher the for the Euro 4-6.

There is also a noticeable difference between the types of fuel. Cold-start emissions from gasoline combustion for all pollutants are higher than for other fuels.

The simulations carried out clearly show that increasing the average speed will reduce the cold-start emissions. The problem of emissions is particularly acute in cities during traffic congestion. It is important to strive to increase the average speed in cities, it will reduce the emission of pollutants from road transport.

The obtained modeling results would be worth comparing with measurements in real traffic conditions, the authors are in the process of conducting such tests.

\section{Nomenclature}

CNG compressed natural gas

$\mathrm{CO}$ carbon monoxide

$\mathrm{CO}_{2} \quad$ carbon dioxide

D diesel oil

LPG liquified petrolum gas

NMVOC non-methane volatile organic compound

$\begin{array}{ll}\mathrm{NO}_{x} & \text { nitrogen oxides } \\ \mathrm{P} & \text { petrol } \\ \mathrm{PCs} & \text { passenger cars } \\ \text { WLTP } & \text { Worldwide Harmonized Light-Duty Vehicles } \\ & \text { Test Procedure }\end{array}$

\section{Bibliography}

[1] ANDRYCH-ZALEWSKA, M., MERKISZ J., PIELECHA J. The influence of the heating time of a catalyst-covered glow plug on the exhaust emissions from a diesel engine. Combustion Engines. 2021, 184(1), 52-56. https://doi.org/10.19206/CE-134738

[2] BRADY, R.N. Internal Combustion (Gasoline and Diesel) Engines. Reference Module in Earth Systems and Environmental Sciences. 2013.

https://doi.org/10.1016/B978-0-12-409548-9.01056-3
[3] BURR, M., GREGORY, C. Vehicular Exhausts. Encyclopedia of Environmental Health (Second Edition). 2011, 335-343. https://doi.org/10.1016/B978-0-444-63951-6.00664-1

[4] CLAIROTTE, M., SUAREZ-BERTOA, R., ZARDINI, A.A. et al. Exhaust emission factors of greenhouse gases (GHGs) from European road vehicles. Environmental Sciences Europe. 2020, 32, 125. https://doi.org/10.1186/s12302-020-00407-5 
[5] EMEP/EEA air pollutant emission inventory guidebook 2019.

[6] GUS (2020). Statistical Yearbook of the Republic of Poland 2019. GUS, 2020.

[7] GUS T (2020). Transport - activity results in 2019. GUS, Warsaw 2020.

[8] LASKOWSKI, P., ZIMAKOWSKA-LASKOWSKA, M. The dependency between methane emissions and the trip length accounting the cold start engine conditions. Proceedings of the Institute of Vehicles. 2019, 1(119), 25-33.

[9] LASKOWSKI, P., ZASINA, D., ZIMAKOWSKA-LASKOWSKA, M. et al. Modelling hydrocarbons cold-start emission from passenger cars. Advances in Science and Technology Research Journal. 2021, 15(3), 117-125. https://doi.org/10.12913/22998624/138764.

[10] Ministry of Climate and Environment. 2021. Poland's Informative Inventory Report. Submission under the UNECE CLRTAP and NEC Directive.

https://cdr.eionet.europa.eu/pl/eu/nec_revised/iir/envyei5sq/

[11] NTZIACHRISTOS, L., GKATZOFLIAS, D., KOURIDIS, C. et al. COPERT: a European road transport emission inventory model. ATHANASIADIS, I.N., RIZZOLI, A.E., MITKAS, P.A. et al. (eds) Information Technologies in Environmental Engineering. Environmental Science and Engineering. Springer, Berlin, Heidelberg. 2009. https://doi.org/10.1007/978-3-540-88351-7_37

Piotr Laskowski, DEng. - Faculty of Automotive and Construction Machinery Engineering, Warsaw University of Technology.

e-mail: piotr.laskowski@pw.edu.pl
[12] SENTOFF, K.M., ROBINSON, M.K., HOLMEN, B.A. Second-by-second characterization of cold-start gas-phase and air toxic emissions from a light-duty vehicle. Transportation Research Record: Journal of the Transportation Research Board. 2010, 2158(1), 95-104. https://doi.org/10.3141/2158-12

[13] CHARLTON, S.J. Chapter 11 - Control Technologies for Compression-Ignition Engines. Handbook of Air Pollution From Internal Combustion Engines. Academic Press. 1998, 358-419. https://doi.org/10.1016/B978-012639855-7/50050-8

[14] SUAREZ-BERTOA, R., ASTORGA, C. Impact of cold temperature on Euro 6 passenger car emissions. Environmental Pollution. 2018, 234, 318-329. https://doi.org/10.1016/j.envpol.2017.10.096

[15] WEILENMANN, M., FAVEZ, J.Y., ALVAREZ, R. Coldstart emissions of modern passenger cars at different low ambient temperatures and their evolution over vehicle legislation categories. Atmospheric Environment. 2009, 43(15), 2419-2429.

https://doi.org/10.1016/j.atmosenv.2009.02.005

[16] WEILENMANN, M., SOLTIC, P.. HAUSBERGER, S. The cold start emissions of light-duty-vehicle fleets: A simplified physics-based model for the estimation of $\mathrm{CO}_{2}$ and pollutants. Science of the Total Environment. 2013, 444, 161-176. https://doi.org/10.1016/j.scitotenv.2012.11.024

Magdalena Zimakowska-Laskowska, DEng.
Institute of Environmental Protection - National
Research Institute.
e-mail: magdalena.zimakowska-laskowska@kobize.pl
Damian Zasina, DEng. - Faculty of Building Ser-
vices, Warsaw University of Technology.
e-mail: damian.zasina@pw.edu.pl
Institute of Environmental Protection - Nationa Research Institute.

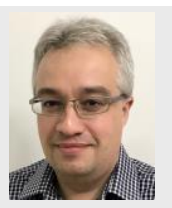

A Iing 